\title{
Del epigrama al hipertexto: Hesperia. Banco de datos de lenguas paleohispánicas
}

From the epigram to hypertext: Hesperia. Palaeohispanic languages Data Bank

José A. Berenguer-Sánchez

ILC, CSIC

j.berenguer@csic.es

La publicación en abierto de la base de datos Hesperia supone un hito de gran relevancia en el estudio de las lenguas paleohispánicas. En esta contribución se repasan las características de esta edición en línea, examinando las diferencias que supone la publicación en línea, basada en las posibilidades del hipertexto, frente a la publicación del texto impreso.

Palabras clave: lenguas paleohispánicas; banco de datos; hipertexto; edición impresa.

The online open access edition of the Hesperia databank is a milestone of great significance in the study of Paleohispanic languages. In this paper are revised the characteristics of this online edition, by examining the differences involved in online publication based on the possibilities of hypertext, compared to print edition.

Key words: Paleohispanic languages; databank; hypertext; print edition.

El pasado 20 de junio de 2014 tuvo lugar en el salón de actos de la Fundación Pastor de Estudios Clásicos, en Madrid, el acto de presentación del Banco de Datos Hesperia (http://hesperia.ucm.es), proyecto conjunto de las Universidades Complutense, del País Vasco, Zaragoza y Barcelona. En el acto, que contó con la presencia del Vicerrector de Relaciones Institucionales e Internacionales de la Universidad Complutense, D. Andrés Arias Astray, así como del presidente del Patronato de la Fundación Pastor, Emilio Crespo, intervinieron distintos miembros del equipo que ha creado este banco de datos. Dieron a conocer sus contenidos y explicaron la historia de su diseño, creación e implementación, sus características esenciales, el estado actual y sus previsiones. Así, tomaron la palabra Javier de Hoz (Universidad Complutense y patrono de la Fundación Pastor de Estudios Clásicos), Joaquín Gorrochategui (Universidad del País Vasco), Eduardo Orduña (IES Pont de Suert), José María Vallejo (Universidad del País Vasco), Eugenio Luján (Universidad Complutense, Decano de su Facultad de Filología), Francisco Beltrán Lloris (Universidad de Zaragoza) y Javier Velaza (Universidad de Barcelona). 
Hesperia es un banco de datos en línea, cuyo objetivo básico es la recopilación, ordenación y tratamiento de todos los materiales lingüísticos relativos a la Península Ibérica, así como los del sur de Francia que pueden ponerse en relación con ella, con exclusión de las inscripciones latinas, griegas y fenicias. Cuando el banco de datos cuente con todo su contenido incorporado y disponible, se tendrá acceso a todos los textos en lenguas paleohispánicas (ibérico, celtibérico, lusitano y lengua del Suroeste). También incluirá las inscripciones monetales paleohispánicas (de hecho ya están disponibles), así como la onomástica indígena transmitida en fuentes epigráficas o literarias grecolatinas y las glosas hispánicas transmitidas por los autores antiguos. Es importante señalar que una de las características fundamentales de Hesperia, que quedó muy clara en la presentación y que constituye sin duda una peculiaridad, afortunadamente cada vez menos notoria, en el ámbito de la filología y el estudio de las lenguas antiguas, es que se basa en la estrecha colaboración de distintos equipos de investigación de distintas universidades españolas. Son equipos de la Universidad Complutense, Universidad del País Vasco, Universidad de Zaragoza y Universidad de Barcelona los que han trabajado conjuntamente en un proyecto coordinado con este fin. En realidad, el proyecto de este banco de datos fue iniciado en 1997 por el Profesor Javier de Hoz, quien ha sido capaz de captar el interés e involucrar en Hesperia a diversos investigadores de esas universidades.

Otra característica muy importante de esta publicación en línea es su carácter de herramienta de acceso abierto, sin restricciones de ningún tipo. Con ello, se da afortunadamente un paso más en la tendencia al open access, por la que bancos de datos y webs de contenidos fundamentales para la investigación en lenguas antiguas, Filología y, en general, en Humanidades, desarrollados por equipos de investigación del más alto nivel, se ponen a disposición del resto de investigadores sin contraprestación económica de ningún tipo. Esto propicia evidentemente la consulta general, la difusión de los contenidos y su conversión en obras fundamentales de referencia. En esa dialéctica que se ha planteado en los últimos años en las publicaciones en línea, entre open access y acceso restringido previo pago, se está observando cómo se impone la lógica de los hechos. Si los equipos de investigación cuentan con financiación pública, y les es posible disponer de personal especializado y desarrollar los diseños informáticos adecuados, es normal que se generen resultados en acceso abierto. Con ellos, los investigadores corresponden y justifican completamente la financiación recibida para esos desarrollos. De ahí la importancia de una adecuada política científica, no cicatera, de financiación de proyectos.

Si analizamos el diseño y funcionamiento de Hesperia, podemos comprobar otro rasgo destacable: el máximo aprovechamiento que se ha dado en su diseño a las posibilidades que ofrece la edición en línea. Como varios de los miembros del equipo demostraron con sus presentaciones, y como verbalizó en concreto el profesor Velaza, las diferencias positivas de un banco de datos como éste, frente a la 
edición impresa tradicional, son realmente notables. Así, frente a la obsolescencia que empieza a aquejar a la edición impresa de un corpus epigráfico tan pronto como aparece editada, la publicación en línea permite actualizaciones regulares, facilitando la consulta inmediata y directa de las novedades en la edición concreta de cada inscripción. Se prescinde de este modo de la consulta de suplementos, que a veces puede llegar a ser realmente farragosa, dada la necesidad de cotejar los datos esparcidos en diversos volúmenes. Otra ventaja innegable de la edición en línea, basada también en la superación de los límites impuestos por la edición impresa, es que las restricciones de espacio han dejado de ser un problema. Esto permite incluir, de modo bien estructurado y claro, todos los materiales que son considerados de interés. Aprovechando este rasgo hay un apartado «Documentación» en el que aparecen varios subapartados: Mapas, Publicaciones, Escrituras, Resumen de bibliografía y Bibliografía general. En el primero de ellos aparecen ya, con posibilidad de consulta y descarga sencilla, mapas muy detallados (en formato.JPG) de las inscripciones prelatinas (y aquí sí se incluyen la referencia a inscripciones griegas y fenicias), de isoglosas ibéricas, de inscripciones anteriores al siglo IV (incluyendo de nuevo, junto a las referencias de las paleohispánicas, las de las griegas y fenicias), mapa de las inscripciones de los siglos IV y III a.C. y mapa de las inscripciones paleohispánicas posteriores al siglo III a.C. y latinas de fecha republicana. Bajo «Publicaciones» se recoge el contenido completo de distintos artículos y trabajos, aparecidos en diversos lugares, en los que miembros del equipo explican y dan información sobre el proyecto. Bajo «Escrituras», aparece una explicación breve de los distintos sistemas gráficos empleados por las lenguas paleohispánicas, con tablas del signario ibérico o nororiental y del signario celtibérico. Estas tablas son «sensibles», de modo que, al situar el cursor sobre la grafía estándar de cada signo, aparecen en línea las distintas variantes gráficas de ese signo. En «Resumen de bibliografía», se ofrece una selección bibliográfica que recoge los trabajos introductorios básicos sobre los aspectos más relevantes relacionados con la epigrafía paleohispánica, ordenada por temas. Las referencias están indicadas de modo abreviado y remiten al listado de la Bibliografía General del Banco de Datos Hesperia, a la que se accede en la última pestaña de la sección de «Documentación». Una bibliografía completamente exhaustiva, con actualizaciones periódicas, que, en el momento actual cuenta con más de cuatro mil referencias.

En el menú principal, además de las pestañas de «Presentación» y «Documentación», puede accederse a la pestaña fundamental «Banco de datos», y a las pestañas «Enlaces», «Noticias» y «Contacto», cuyos contenidos resultan evidentes. En la primera línea, bajo el título, aparecen además seis botones que son también fundamentales: cuatro de ellos aparecen con nombre («Base Epigráfica», «Numismática», «Bibliografía» y «Mapas»), mientras que los dos restantes aparecen con el icono de una lupa tras los dos primeros que acabamos de citar. Mediante estos 
botones se accede de modo directo a partes esenciales del Banco de Datos o a sistemas de búsqueda de esas secciones. Según se informó en la presentación, y aparece especificado en la propia web del proyecto, el diseño general ha sido desarrollado por Eduardo Orduña recurriendo a software libre y de código fuente abierto. Se partió de un diseño de ficha realizado en File Maker por Fernando Quesada, adaptado en sus detalles a cada una de las bases.

Hesperia se estructura como una serie de bases relacionadas entre sí: Epigrafía, Numismática, Onomástica, Léxico y Bibliografía. Pero además cuenta con dos herramientas suplementarias relacionadas con las demás bases: la aplicación MapServer, desarrollada por la Universidad de Minnesota, que genera mapas de distribución de localizaciones que cumplan con un determinado patrón de búsqueda, y el buscadorgenerador de Gráficos. Las posibilidades de consulta que se abren para el investigador son enormes, y el aprovechamiento de las potencialidades que ofrece hoy en día la publicación en línea es máximo, por lo que Hesperia puede empezar a citarse, sin duda, como un ejemplo claro de los desarrollos que pueden lograrse actualmente en la edición de cualquier herramienta filológica en línea.

La intención del equipo es mantener permanentemente actualizado el Banco de Datos, lo que permitirá la inclusión de material nuevo, ya sean nuevas inscripciones u otro tipo de material, así como reinterpretaciones de datos antiguos. Sin duda, junto al reto de completar el contenido básico de Hesperia, dado que de momento sólo está disponible una parte, el mantenimiento y actualización de los datos introducidos va a ser una de las labores fundamentales del proyecto en el futuro. En el momento de su presentación, se han puesto a disposición pública las inscripciones paleohispánicas correspondientes a las regiones Narbonense y Celtibérica, y la Base Numismática. A medida que el equipo vaya concluyendo la edición de los textos de las otras regiones epigráficas o las bases onomásticas, se irán poniendo también a disposición pública. Por lo tanto, de las diez regiones claramente especificadas en el mapa inicial que aparece al acceder a la web, están pendientes de ser incorporados los datos correspondientes a ocho de ellas, si bien es cierto que el interés y posibilidad de consultar ya las dos regiones incorporadas, Narborense y Celtibéricas, así como de los datos numismáticos, justifica con creces la presentación del Banco de Datos en este momento.

La pestaña «Banco de datos» se subdivide en varias pestañas de acceso a cada una de las bases citadas. En el caso de la base de «Epigrafía», que puede considerarse el núcleo central de Hesperia, se observa la existencia de dos enlaces fundamentales cuando se entra en ella: «Acceso abierto», por el que se accede a las partes ya publicadas, y «Acceso restringido», que cabe suponer que permite a los miembros del equipo el acceso a las partes en proceso de elaboración o secciones internas. En realidad, esta vía de entrada al Banco de datos es más larga que el acceso directo a través del mapa de la página de inicio, sobre el que, con dos clics, se entra en la 
sección de la Base epigráfica correspondiente a la sección que nos interesa. Es esa sección, se ofrece la posibilidad de un acceso rápido a las inscripciones, bien por medio de una selección en un mapa del lugar concreto que nos interesa, bien a través de un índice de localidades, con una codificación sencilla. Al llevar a cabo la selección correspondiente, se despliega de forma inmediata un listado de datos, donde se menciona el nombre del yacimiento, la referencia según los Monumenta Linguarum Hispanicarum de Untermann, la referencia de Hesperia, el texto de la inscripción y un enlace a la ficha correspondiente. Resulta curioso, y también práctico, que en el listado de registros aparezca ya el texto completo de cada inscripción, incluso cuando se trata de inscripciones extensas, como los bronces de Botorrita. La referencia de Hesperia es la referencia identificadora de la inscripción en el Banco de Datos. Esta referencia responde a una codificación sencilla: en primer lugar en letras mayúsculas aparece la abreviatura de la provincia española (dos letras) o provincia portuguesa y departamento francés (tres letras), en el que ha aparecido la inscripción; a continuación la cifra que indica el yacimiento, al que le sigue otra cifra que hace referencia a la inscripción concreta. En el caso en que haya más de una inscripción sobre un mismo soporte, se identifican por letras a, b, c, etc. Para casos de procedencia desconocida la abreviatura inicial es SP. Si desde el listado se sigue el enlace a la ficha correspondiente, apreciaremos un formato de ficha que visualmente recuerda mucho el diseño original en File Maker.

Cada ficha epigráfica consta de seis pestañas. La pestaña «Generalidades» ofrece la información relativa al soporte y a los rasgos físicos de la inscripción. "Texto» nos muestra el texto de la inscripción con un sistema que permite visualizar cómodamente su aparato crítico. En lugar de aparecer éste bajo el texto principal, que en el caso de inscripciones extensas haría más incómoda la consulta, permite visualizar las variantes al colocar el cursor sobre una palabra. Para señalar que una palabra o una frase tienen variantes o anotaciones en el aparato crítico se usa el color azul, mientras que el texto que carece de ellas aparece en negro. Un sistema éste que ya hemos observado en otras ediciones en línea de otras especialidades, y cuyo uso parece que va extendiéndose. Este sistema es muy cómodo para la consulta inmediata, pero cabría introducir todavía una mejora: la posibilidad no sólo de ver, sino también de acceder a la ventana en que aparecen las variantes, de modo que pudieran copiarse directamente. A efectos de anotación en papel, por parte de quien consulta la base, no es problema, evidentemente, pero a efectos de copia de datos en documento o herramienta electrónica aparte, sí. Por otro lado, otra mejora que sería muy notable y que, en esta contraposición que estamos planteando entre hipertexto y edición impresa, sería también perfectamente viable llevar a cabo con la edición en línea es la de extender algo más las referencias de los autores de la correcciones, o bien enlazarlas con el dato bibliográfico o referencia concreta. Que en un aparato crítico aparezcan las iniciales o la mención más sucinta posible del autor de una corrección 
es una práctica impuesta por el formato de la edición impresa tradicional, donde las razones de espacio obligan a esas referencias absolutamente sintéticas. Ésta es una de las exigencias del formato impreso que se siguen arrastrando, de modo prácticamente inadvertido en las ediciones electrónicas, y que podría superarse con las posibilidades del nuevo formato electrónico. Como señalo, no sería preciso, si se quiere, prescindir de la referencia sintética. Bastaría con enlazar esa abreviatura con la referencia completa. Algo como lo que de hecho se hace en la pestaña «Bibliografía», donde no aparecen las referencias bibliográficas completas, sino sólo la referencia corta basada en nombre de autor y año. Cuando el cursor se sitúa sobre ella, marcada también en azul, aparece en una ventana la referencia completa, enlazada lógicamente desde la base de datos de bibliografía. Y aquí se echa de menos la misma posibilidad que señalaba con respecto a la ventana de aparato crítico: la posibilidad de acceso y copia de esa referencia, no sólo de visualización. Obviamente, detrás de estas observaciones que hago, y del modo en que ahora mismo aparecen en la ficha de la web, hay sin duda razones técnicas que probablemente justifican sobradamente que la forma de aparición de los datos sea la que es. No obstante, precisamente por el enorme avance que supone la publicación de este Banco de Datos, nos parece que sería interesante estudiar para un futuro esas posibles. Hay con todo, un dato a tener en cuenta. Aunque en la presentación no se aludió a ello, en la web de Hesperia se informa de que todo el contenido de la Base Epigrafía, incluidas las ilustraciones, aparecerá también en lo que se califica de «publicación digital», divida en volúmenes y fascículos según la región epigráfica concernida. El volumen I, fasc. I del Banco de Datos Hesperia recogería toda la información introducida en la Base Epigrafía, correspondiente a las inscripciones paleohispánicas procedentes de la región Narbonense, mientras que el volumen I, fasc. II, recogería por su parte la edición de todas las inscripciones celtibéricas. Estas publicaciones «digitales» serán editadas por el Servicio Editorial de la Universidad del País Vasco. Interpretamos que se está aludiendo a una edición digital impresa. Esto es, a una publicación de una versión en papel de la edición electrónica. Ésta es una opción que se está adoptando en algunas editoriales, generalmente bajo el procedimiento de la «impresión bajo demanda», para compatibilizar las dos formas de publicación. Evidentemente la necesidad de compatibilizar ambos tipos de publicación puede condicionar cuestiones relativas a la formalización de los datos, como las que acabo de mencionar.

El resto de pestañas de la ficha epigráfica («Epigrafía y Paleografía», «Ilustraciones» $\mathrm{y}$ «Contexto Arqueológico») reúnen también información muy relevante sobre cada inscripción, demostrando una vez más las posibilidades y ventajas de la edición en línea. La ficha se complementa con una serie de botones disponibles en el lado derecho, para moverse dentro del fichero y para buscar todo tipo de datos.

Precisamente los sistemas de búsquedas de Hesperia constituyen uno de sus rasgos más destacables. Son sistemas de búsquedas muy completos, sencillos de manejo 
y que permiten todo tipo de resultados. Se proponen diversos niveles de búsqueda por todos los campos posibles. Una vez enviada la solicitud y obtenida la selección, puede generarse un mapa de distribución de las inscripciones de la selección o guardar los datos en un documento PDF, que se genera de modo muy fácil y con una excelente calidad, que incluye no sólo textos, sino también imágenes.

En conclusión, puede afirmarse que la publicación en línea del Banco de Datos Paleohispánicos Hesperia, largo tiempo anunciada y esperada, no ha defraudado las expectativas. Todo lo contrario. Es un ejemplo de publicación filológica en línea, en el que se han aprovechado todas las posibilidades que ofrece este nuevo formato, frente al formato impreso, y que, desde ahora, tendrá que añadirse a otras webs creadas por equipos internacionales, como ejemplo y referencia de cómo pueden orientarse las ediciones en línea dentro del estudio de las lenguas antiguas. 